\title{
Study of White-rot Fungus Immobilization on Leather Dye Wastewater Treatment
}

\author{
by
}

Shan $\mathrm{CaO}^{1}$, Xudong $\mathrm{Xu}^{1}$, Deyi Zhu ${ }^{1}$, Changhua Jiang ${ }^{2}$, Tianping $\mathrm{Yu}^{2}$, Yanchun Li *1,

1. School of Light Industry and Engineering, Qilu University of Technology (Shandong Academy of Sciences), Jinan, Shandong Province, 250353, China

2. Shandong Leather Industry Research Institute, Jinan, Shandong Province, 250021, China

*Corresponding author: Yanchun Li

Email: qlulyc@126.com 


\begin{abstract}
The dye effluent is usually difficult to be degraded by conventional wastewater treatment in leather industry. In order to develop efficient and cost-effective treatment methods, we evaluate the effect of white-rot fungus immobilization for dye decolorisation in this paper. The Phanerochaete chrysosporium BKM-F-1767 was used for immobilization. This research found that the white-rot fungus immobilization had an obviously decolorisation effect in dye wastewater treatment, and plant carriers such as sorghum stalk and corn cob were helpful to the growth of Phanerochaete chrysosporium in white-rot fungus immobilization. Due to the stability and recyclability, the white-rot fungus co-immobilization was considered as the most suitable treatment for decolorisation of dye effluent which enjoyed the advantages of both adsorption immobilization and entrapment immobilization. Furthermore, the dye decolorisation evaluation was carried out to find the most suitable carrier for co-immobilization, and it found that sorghum stalk - calcium-alginate gel spherical particle (SS-CGPB) has better decolorisation effect than corn cobs - calcium-alginate gel spherical particle (CC-CGPB), and the dye decolorisation rate was $86.77 \%$. After 5 cycles, the dye decolorisation rate was $85.87 \%$ which indicated the SS-CGPB preserved functional integrity successfully. By further analyzing the biodegradation process with white-rot fungus immobilization, the intermediate products were observed and the degradation pathway of acid golden yellow dye molecular was proposed. The results showed that the $\mathrm{C}-\mathrm{N}$ single bonds attached to the central benzene in the dye molecule were attacked and destroyed in white-rot fungus co-immobilization treatment, thus the structure of dye molecule could be successfully degraded into small molecules which would be more easily treated by conventional treatment methods. Therefore, the white rot fungus co-immobilization might be appropriate for pre-treatment as an important biotechnology for the advanced treatment of dye effluent.
\end{abstract}

Key words: White rot fungus; Co-immobilization; Dye wastewater treatment; Dye decolorisation; Acid golden yellow dye. 


\section{Introduction}

White-rot fungus can degrade chemicals including polyaromatic hydrocarbons, polychlorinated biphenyls, halogenated aromatics, some dyes and other toxic chemicals, (Baratto et al. 2015) because it secretes many types of extracellular oxidase including laccase, manganese peroxidase and lignin peroxidase.(Riley et al. 2014) Therefore, it has the potential to apply for degrading persistent organic pollutants in industry and has attracted attention from many researchers in recent years.(Yao et al. 2018) Compared to other biodegradation systems, the white-rot fungus system has a variety of advantages such as low specificity and the pre-acclimatization to chemicals is not necessary.(Zhang et al. 2008) The major problem of white-rot fungus system in practical application is that, the microorganisms have low stability in a complex environment due to their poor anti-adversity.(Rauf et al. 2010) To overcome the limitations, the immobilization method should be considered as an effective technology to improve the degradation efficiency of pollutants treatment owing to its high processing efficiency, good stability, broad environmental tolerance and easy solid-liquid separation.(Hisaindee et al. 2013)

Compared to free fungal cells, immobilized fungi cells display obviously advantages because it can make the system more resilient to environmental perturbations and provide the convenience for regeneration. The commonly methods for immobilized microorganisms include entrapment method and adsorption method.(Yang et al. 2015) In entrapment method, the microorganisms can be immobilized by physical entrapment inside a polymer or a gel matrix, while adsorption method involves the physical binding of cells on the surface of carriers. Furthermore, both fungal cells and the enzyme produced by the fungus can be immobilized in the white rot fungus immobilization. 
The degradation capacity of this system can be improved and the operation prevents washout of biomass.(Natarajan et al. 2011) In recent years, co-immobilization system is developed, where two or more bioactive ingredients can be immobilized simultaneously in order to provide synergistic effect.(Kariminiaae-Hamedaani et al. 2007)

The immobilized carriers can be usually classified as organic/inorganic or natural/synthetic. The ideal carriers should be insoluble, non-toxic, easily accessible, inexpensive, stable and suitable for regeneration.(Saratale et al. 2011) while the immobilization process should be simple with mild conditions. Up to now, there are many carriers such as sodium alginate, polyvinyl alcohol (PVA), and some plant-derived materials have been applied for cell immobilization. (Bilal et al. 2017) By characterizing the structure of plants tissues, they usually possess a complex internal microstructure in which the pores are fairly large. Thus the plant materials offer the possibility for cell immobilization as carriers owing to their microstructure.(Varjani 2017) Mohammadi developed a system for the degradation of polycyclic aromatic hydrocarbons by immobilizing the white rot fungus on bagasse.(Fuchs et al. 2011) Li explored the utilization of white rot fungus immobilized in wood chips to remove carbamazepine and naproxen. The results showed complete removal of naproxen and 60 - 80\% removal of carbamazepine were obtained in the first two weeks.(Zhao et al. 2016) Meanwhile, polyvinyl alcohol (PVA) is also a promising carrier for cell immobilization owing to its non-toxic, high water affinity, good biocompatibility and minimal cell and protein adhesion.(Rushton and Mokaya 2008) Surkatti used Pseudomonas putida immobilized in PVA gel to treat simulated p-cresol wastewater. (Chandra et al. 2011) Furthermore, Farkas studied the kinetic and equilibrium of phenol biosorption on immobilized white rot fungus Phanerochaete chrysosporium.(Chaudhary et al. 2017) 
In this study, different dyes and different carriers applied in dye decolorisation were analyzed to find the suitable materials for white rot fungus immobilization. Afterwards, different immobilization methods were used to immobilize white-rot fungus, and the effective immobilization method was decided by evaluating the decolorisation rate. Then the dye decolorisation pathway with co-immobilization was analyzed. This research was significant and meaningful to dye decolorisation by biodegradation methods

\section{Experimental}

\section{Materials}

Different dyes were obtained from Yadong Chemical \& Dyestuff Factory (Tianjin, China) such as magenta dye, reactive red dye, reactive blue dye, acid black dye, acid golden yellow dye, direct green dye and direct blue dye. The agents used for chemical analysis were of analytical grade and purchased from Damao Chemical Reagent Factory (Tianjin, China), while agents used for fungal culture were obtained from AoBoxing Bio-Tech Co., LTD (Beijing, China). The Phanerochaete chrysosporium BKM-F-1767 was purchased from the Guang dong Microbiological Culture Center. The leather dyeing wastewater used for observing the decolorisation effect was collected from Polygrace Co.,LTD (Zibo, China).

\section{Pre-preparation}

\section{Preparation of culture medium}

The trace element solution was firstly prepared which consisted of $1.0 \mathrm{~g} / \mathrm{L} \mathrm{NaCl}, 3.0 \mathrm{~g} / \mathrm{L}$ $\mathrm{MgSO}_{4} .7 \mathrm{H}_{2} \mathrm{O}, 100 \mathrm{mg} / \mathrm{L} \mathrm{FeSO}_{4} .7 \mathrm{H}_{2} \mathrm{O}, 100 \mathrm{mg} / \mathrm{L} \quad \mathrm{CoSO}_{4} .7 \mathrm{H}_{2} \mathrm{O}, 100 \mathrm{mg} / \mathrm{L} \mathrm{CaCl} \mathrm{Cl}_{2}, 100 \mathrm{mg} / \mathrm{L}$ $\mathrm{ZnSO}_{4} .7 \mathrm{H}_{2} \mathrm{O}, 10 \mathrm{mg} / \mathrm{L} \mathrm{CuSO}_{4} .5 \mathrm{H}_{2} \mathrm{O}, 100 \mathrm{mg} / \mathrm{L} \mathrm{KAl}\left(\mathrm{SO}_{4}\right)_{2}, 10 \mathrm{mg} / \mathrm{L} \mathrm{H}_{3} \mathrm{BO}_{3}, 10 \mathrm{mg} / \mathrm{L} \mathrm{Na}_{2} \mathrm{MoO}_{4}$. 
Then the liquid medium contained $20 \mathrm{~g} / \mathrm{L}$ glucose, $2 \mathrm{~g} / \mathrm{L} \mathrm{KH}_{2} \mathrm{PO}_{4}, 0.25 \mathrm{~g} / \mathrm{L} \mathrm{MgSO}_{4}, 0.1 \mathrm{~g} / \mathrm{L} \mathrm{CaCl}_{2}$, $5 \mathrm{mg} / \mathrm{L} \mathrm{MnSO}_{4}, 15 \mathrm{mg} / \mathrm{L} \mathrm{VB}_{1}, 0.2 \mathrm{~g} / \mathrm{L}$ ammonium tartrate, and $150 \mathrm{ml} / \mathrm{L}$ trace element solution. Meantime, potato agar medium was prepared for culturing the Phanerochaete chrysosporium,(Kariminiaae-Hamedaani et al. 2007) which contained $200 \mathrm{~g}$ potato lixivium, $20 \mathrm{~g}$ glucose, $20 \mathrm{~g}$ agar, $3 \mathrm{~g} \mathrm{KH}_{2} \mathrm{PO}_{4}$ and $1.5 \mathrm{~g} \mathrm{MgSO}_{4}$. Then the fungus were transferred from potato agar medium into liquid medium, and cultured in an incubator for five days $\left(39^{\circ} \mathrm{C}, 100 \mathrm{r} / \mathrm{min}\right)$.

\section{Preparation of culture medium}

Different dyes were used for analyzing the decolorisation rate initially with $50 \mathrm{mg} / \mathrm{L}$ concentration at $26{ }^{\circ} \mathrm{C}$ for 8 days. The dyes included magenta dye, reactive red dye, reactive blue dye, acid black dye, acid golden yellow dye, direct green dye and direct blue dye, which were usually applied in leather dyeing process Besides, different materials were used for selection of suitable carriers in immobilization such as sorghum stalks, corn cobs, bitter melon seeds, pomegranate seeds, walnut shells, peanut shells and activated carbon.

\section{Fungal Immobilization}

\section{Adsorption Immobilization}

After culturing for five days, $3.36 \mathrm{~g}$ fungal inoculant (Wet weight) was mixed with $100 \mathrm{ml}$ distilled water and shocked at $15^{\circ} \mathrm{C}$ for $3 \mathrm{~min}$ Then $5 \mathrm{ml}$ solution was transferred to the culture medium which contained different dyes. Afterwards, $0.1 \mathrm{~g}$ adsorption carriers (i.e., activated carbon, sorghum stalk, and corn cobs) were also added in the medium respectively, and the adsorption immobilizations were all carried out at $15^{\circ} \mathrm{C}$.

\section{Entrapment Immobilization}

Three entrapment immobilization methods were used to prepare calcium-alginate gel 
spherical particles for immobilizing white rot fungus in this research. The $3.36 \mathrm{~g}$ fungal inoculant (Wet weight) was mixed with $40 \mathrm{ml}$ distilled water, and $60 \mathrm{ml}$ agar at $15{ }^{\circ} \mathrm{C}$ for $3 \mathrm{~min}$, and sodium alginate solution was added ( $2 \mathrm{~g}$ agar and $0.75 \mathrm{~g}$ sodium in $60 \mathrm{ml}$ distilled water) at $15^{\circ} \mathrm{C}$. Then 5 $\mathrm{ml}$ mixture was added into $2.5 \%(\mathrm{w} / \mathrm{w})$ calcium chloride solution to form spherical particles. These microspheres were transferred into phosphate buffer $\left(1.460 \% \mathrm{~K}_{2} \mathrm{HPO}_{4} / 0.226 \% \mathrm{KH}_{2} \mathrm{PO}_{4}\right.$, $\mathrm{w} / \mathrm{w}$ ). After $1 \mathrm{~h}$, the mixture was filtered and calcium-alginate gel spherical particles A (CGP-A) were obtained. Meantime, for preparing calcium-alginate gel a spherical particle B (CGP-B), 3.36 g fungal inoculant (Wet weight) was mixed with $40 \mathrm{ml}$ distilled water at $15^{\circ} \mathrm{C}$, and then $60 \mathrm{ml}$ sodium alginate solution ( $2 \mathrm{~g}$ sodium alginate in $60 \mathrm{ml}$ distilled water) was added. $5 \mathrm{ml}$ mixture was transferred into the $2 \%$ calcium chloride solution and filtration was performed after $2 \mathrm{~h}$. Furthermore, in calcium-alginate gel a spherical particle C (CGP-C) preparation process, $3.36 \mathrm{~g}$ fungal inoculant (Wet weight) was dissolved in $10 \mathrm{ml}$ distilled water. Then, the liquid was mixed with $90 \mathrm{ml}$ of polyvinyl alcohol and sodium alginate solution (12\% PVA, 2\% sodium alginate; w/w). $5 \mathrm{ml}$ mixture was transferred into the saturated boric acid solution with $2 \%$ calcium chloride (w/w). After $50 \mathrm{~min}$, the CGP-C products were collected.

\section{Co-immobilization}

In co-immobilization, $3.36 \mathrm{~g}$ fungal inoculant (Wet weight) was mixed with $40 \mathrm{ml}$ distilled water and shook at $15{ }^{\circ} \mathrm{C}$ for $3 \mathrm{~min}$, and $0.1 \mathrm{~g}$ adsorption carries such as activated carbon, sorghum stalk, and corn cobs were added, separately. Then $60 \mathrm{ml}$ sodium alginate solution mentioned previously was added in these solutions and $5 \mathrm{ml}$ mixture was reacted with $2 \%$ calcium chloride solution for $2 \mathrm{~h}$. Afterwards, different calcium-alginate gel spherical particles produced by co-immobilization were obtained including activated carbon - calcium-alginate gel spherical 
particle (AC-CGPB), sorghum stalk - calcium-alginate gel spherical particle (SS-CGPB) and corn cobs - calcium-alginate gel spherical particle (CC-CGPB). Meantime, $3.36 \mathrm{~g}$ fungal inoculant (Wet weight) was transferred in $10 \mathrm{ml}$ distilled water and $0.1 \mathrm{~g}$ different adsorption carries including activated carbon, sorghum stalk, and corn cobs were added, respectively. Then $90 \mathrm{ml}$ of polyvinyl alcohol and sodium alginate solution was pipetted into the solution, and $5 \mathrm{ml}$ mixture was transferred into the saturated boric acid solution with $2 \%$ calcium chloride with 50 min to form different co-immobilization calcium-alginate gel spherical particles (AC- CGPC, SS-CGPC, and CC- CGPC).

\section{Evaluation of Dye Decolorisation}

\section{Decolorisation Rate}

The UV-2550 UV-vis spectrophotometer was used for analyzing the dye decolorisation. The absorbance of acid golden yellow dye wastewater before and after decolorisation were observed at $450 \mathrm{~nm}$ and further calculated by following formula (1), (Holkar et al. 2014) where $A_{t}$ was the absorbance of decolorized solution at time, $A_{0}$ was the absorbance of the original dye solution, and $\mathrm{E}$ was decolorisation rate.

$$
\mathrm{E}=\left(A_{0}-A_{t}\right) / A_{0} \times 100 \%
$$

\section{Influence of Fungal Immobilization to Dye Decolorisation}

In order to observe the decolorisation effects of different immobilization methods, the Phanerochaete chrysosporium were immobilized by adsorption immobilization, entrapment immobilization and co-immobilization, respectively. Acidic golden yellow dye was added in their liquid culture mediums which the concentration were adjusted to $50 \mathrm{mg} / \mathrm{L}$. Then the decolorisation efficiency of these samples was continuously measured at $39^{\circ} \mathrm{C}$ for 7 days. 


\section{LC-MS Analysis}

The acid golden yellow dye liquid was prepared to simulate the leather dyeing wastewater with the dye concentration of $50 \mathrm{mg} / \mathrm{L}$, and it was decolorized by white rot fungus co-immobilization. Then the liquids before and after decolorisation were freeze-dried. The samples were dissolved in acetonitrile and water, and they were further analyzed by liquid chromatography mass spectrometry (LC-MS) as Baratto's methods.(Baratto et al. 2015)

\section{Evaluation of Fungal Immobilization to treat dye-retanning wastewater}

The dye-retanning wastewater was collected from Polygrace Co., LTD(Zibo-, China). 2g co-immobilization calcium-alginate gel spherical particles were added in $100 \mathrm{ml}$ dye-retanning wastewater and reacted for 7 days. Change of total organic carbon (TOC) influenced by white rot fungus co-immobilization was analyzed by a total organic carbon analyzer (Shimadzu, Japan).(Fang et al. 2017) In this treatment, aeration mixing and shake were carried out to improve the decolorized efficiency.

\section{Results and Discussion}

\section{Dyes and Carries Selection for Fungal Immobilization}

In dye decolorisation by fungal immobilization treatment, the effect is usually influenced by the types of dyes and carriers.(Saratale et al. 2011) Therefore, different dyes and carriers were applied, and the decolorisation effects were evaluated to select suitable dye and carrier for fungal immobilization (Figure 1). Due to different structure of dyes, it founds that most of dyes could be decolorized with Phanerochaete chrysosporium treatment especially acid golden yellow dye, direct blue dye and direct green dye. The decolorisation rates of acid golden yellow dye and direct 
blue dye were $86.77 \%$ and $85.96 \%$, respectively (Figure 1a). It might be resulted by the similar molecular structure of $\mathrm{N}=\mathrm{N}$ attached to benzene ring. Therefore, the acid golden yellow dye was selected to be used in subsequently dye decolorisation. Meantime, in order to choose proper carrier for fungal immobilization, a series of carriers were also been measured including sorghum stalks, corn cobs, bitter melon seeds, pomegranate seeds, walnut shells, peanut shells, and activated carbon (Figure 1b). The results showed that the activated carbon displayed the best decolorized property. In the first $4 \mathrm{~d}$, the decolorisation rates, which of activated carbon, sorghum stalk and corn cob, were all over 50\%. Meantime, it was seen that their decolorisation rates were over70\% in $6 \mathrm{~d}$. Thus these three materials were selected and used for further different immobilization methods analysis.
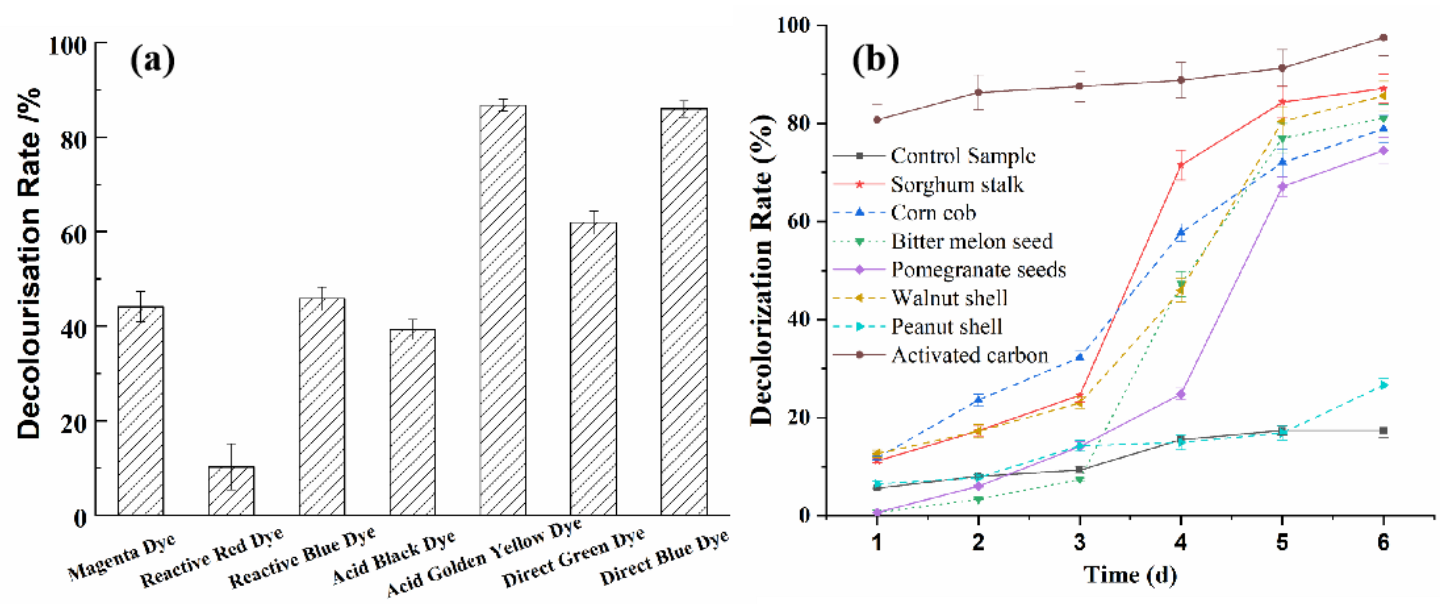

Figure 1. Selection of dyes and carriers used for Phanerochaete chrysosporium immobilization to treat dye wastewater.

(a) Selection of different dyes; (b) Selection of different carriers.

\section{Evaluation of Different Immobilization Methods}

It is known that the immobilization methods influence growth of white rot fungal and the efficiency of producing enzyme, which are directly corresponding with the dye decolorisation.

(Bilal et al. 2017) Therefore, different immobilization methods, including adsorption immobilization, entrapment immobilization and co-immobilization, were applied to treat 
simulated dye wastewater. From Figure $2 \mathrm{a}$ and Figure $2 \mathrm{~b}$, it was seen that adsorption immobilization with activated carbon could improve the decolorisation effect obviously and it may be more suitable than entrapment immobilization in dye decolorisation. The decolorisation rate reached $96.89 \%$ by activated carbon adsorption. However, though the dye decolorisation by activated carbon is efficiency, it is inconvenient for recycling and regeneration of activated carbon in actual wastewater treatment.(Yao et al. 2018) Therefore, from Figure 2a and Figure 2c, it could be concluded that co-immobilization has a higher priority for dye decolorisation than absorption immobilization. It is known that the white rot fungus is usually screened from decayed woods (Riley et al. 2014), and it has good growth performance and high adaptability in the plant matrixes. As shown in Figure 2c and 2d, it found that SS-CGPB took an advantage in dye decolorisation at 6 days and the decolorisation rate reached $86.77 \%$. It could be contributed to that SS-CGPB contained more active ingredients than other carriers, which could provide the nutrients for the growth of cells thereby immobilizing white-rot fungus effectively. Therefore, the positive effect of dye decolorisation with SS-CGPB was resulted by both the absorption effect of SS-CGPB and biodegradation effect of Phanerochaete chrysosporium including cells and enzymes. The steadily increasing decolorisation rate in 4 days should be mainly resulted by the absorption effect, and the rapid rising decolorisation rate after 4 days should be contributed by the biodegradation of white-rot fungus on the phase of logarithmic growth. (Zhang et al. 2008) 

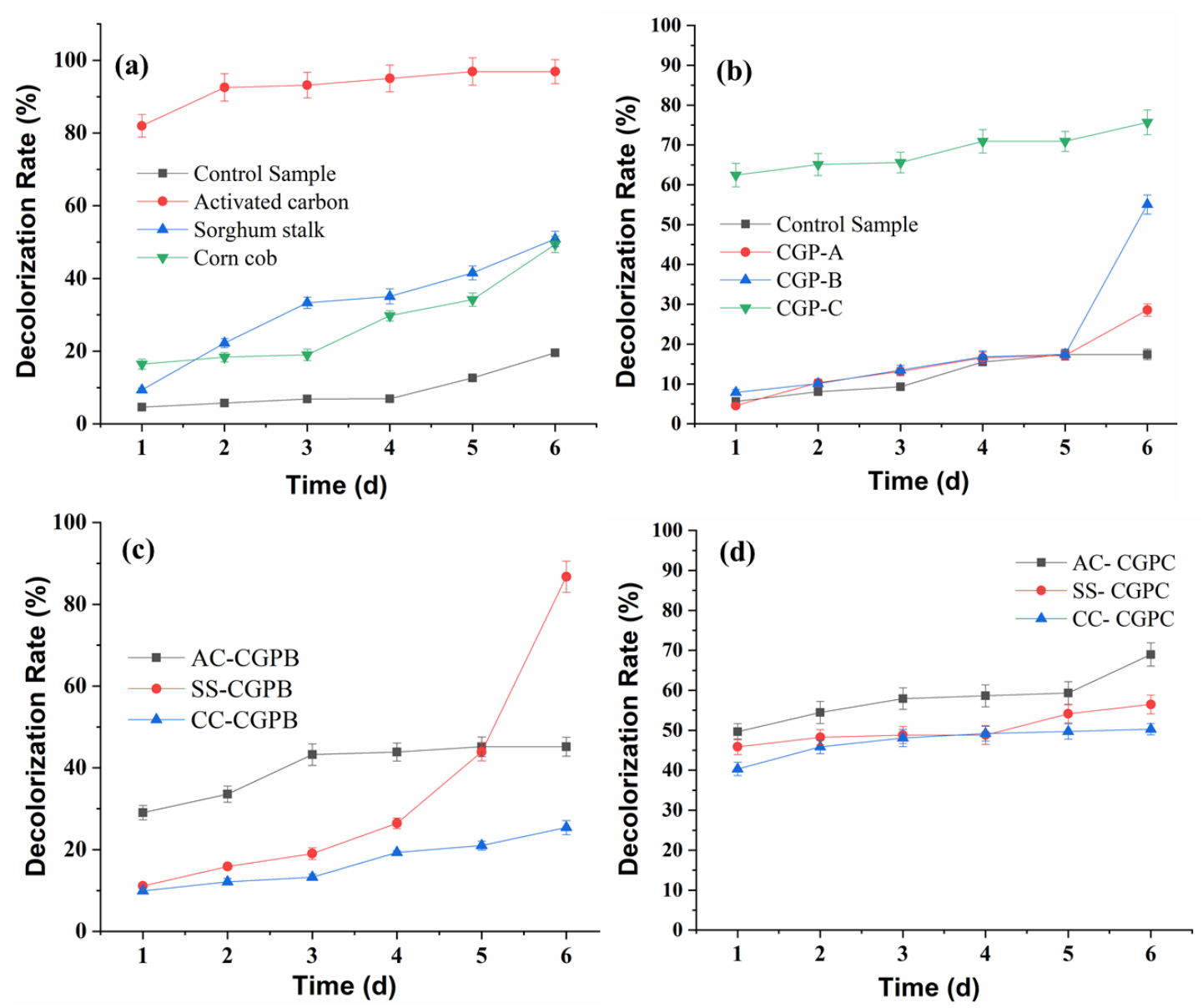

Figure 2. Comparison of different Phanerochaete chrysosporium immobilization methods. (a) Absorption immobilization; (b) Entrapment immobilization; (c) Co-immobilization to prepare calcium-alginate gel spherical particles; (d) Co-immobilization to prepare calcium-alginate gel spherical particles with PVA.

\section{Dye Decolorisation Observation}

In co-immobilization with SS-CGPB to treat dye wastewater, the structures of co-immobilized white-rot fungus were observed as shown in Figure 3. The carrier could provide nutrients for the growth of white-rot fungus, while the embedding materials increased the stability of co-immobilization. It showed that the particles were transparent before decolorisation, and the hyphae could be seen obviously in the gel particle. After dye decolorisation, the color of particles turned to yellow which indicated that it adsorbed dye successfully. The decolorisation effect was significantly which should be contributed to the existence of a large number of hyphae and high specific surface area of the gel particles. After washing with water, there particles could be collected and reused at least 5 times. The decolorisation rates for the first, second, third, fourth and 
fifth reuses were $86.77 \%, 87.15 \%, 87.71 \%, 85.19 \%$ and $85.87 \%$, respectively. According to the observation, it found that these gel particles preserved functional integrity and exhibited excellent performance after 5 cycles. Based on these results, the co-immobilized system showed good decolorisation effect when the concentration of dye in the wastewater was $50 \mathrm{mg} / \mathrm{L}$ and the gel particles exhibited high performance for dye decolorisation.

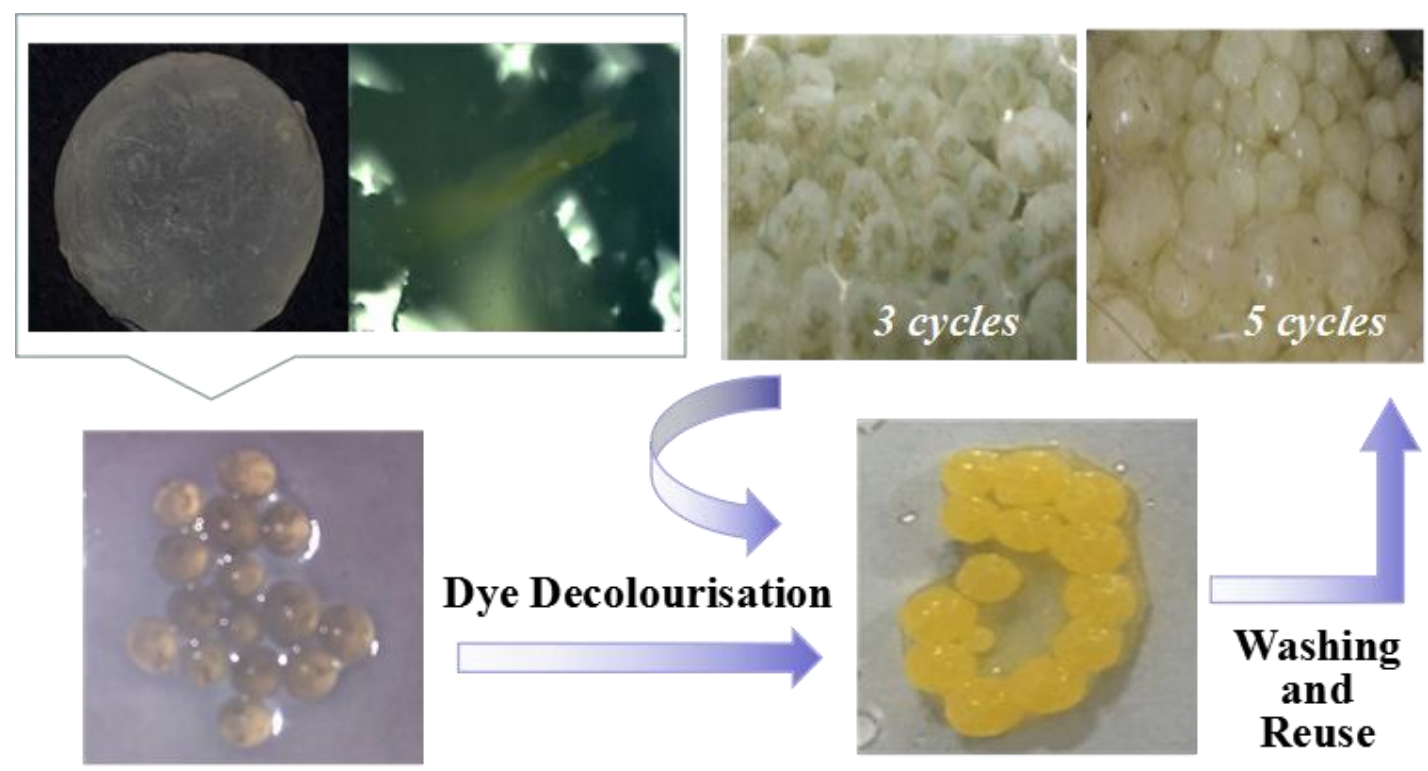

Figure 3. Observation of SS-CGPB in dye decolorisation

\section{LC-MS analysis}

LC-MS analysis can be used to analyze the composition of intermediate products in degradation, (Rauf et al. 2010) and the results are shown in Figure 4. In addition to the peak of acid golden yellow, there are many other peaks observed in Figure 4 due to the complex composition of simulated dye wastewater. It was resulted by the existence of enzyme produced by white-rot fungus. Thus the components in dye-retanning wastewater after dye decolorisation would be more complicated than that before dye decolorisation. The structures of some intermediate products from degradation of acid golden yellow dye were predicted. By observation with LC-MS, it was seen that the mass spectra of the intermediate degradation products separated 
at different retention time were corresponding with the predicted structures. The acid golden yellow dye was detected with $\mathrm{m} / \mathrm{z}$ 383. It showed that the intensity of this peak decreased obviously after dye decolorisation (Figure 4a \& Figure 4b), which represented that the acid golden yellow dye was degraded successfully using co-immobilization treatment. Furthermore, the potential degradation products were confirmed through analyzing of peaks of the fragment ion mass spectrum including m/z 78 at $4.72 \mathrm{~min}$ (Figure 4c), m/z 175, m/z 282 at $5.78 \mathrm{~min}$ (Figure 4d) and $\mathrm{m} / \mathrm{z} 81, \mathrm{~m} / \mathrm{z} 168$ at $8.25 \mathrm{~min}$ (Figure 4e). The appearance of these peaks indicated the structure of acid golden yellow dye had been cleaved. It found that there were 5 intermediate products after dye decolorisation, and the pathway of degradation would be analyzed in detail in the following.
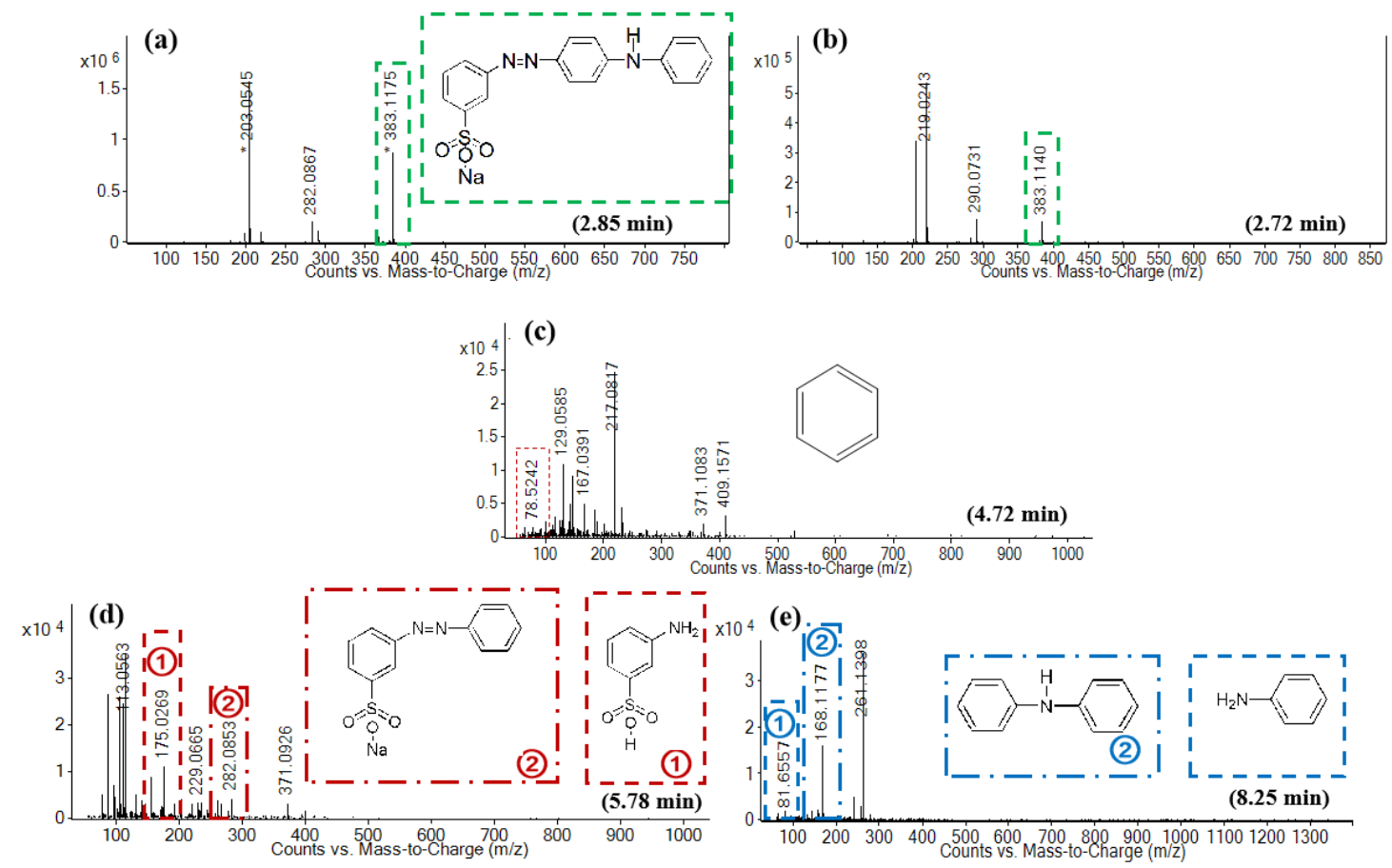

Figure 4. LC-MS analysis of simulated dye wastewater. (a) Untreated dye wastewater at 2.72 min; (b) Decolorized dye wastewater at $2.72 \mathrm{~min}$; (c) Decolorized dye wastewater at $4.72 \mathrm{~min}$; (d) Decolorized dye wastewater at 5.78 min. (e) Decolorized dye wastewater at 8.25 min.

\section{Proposed mechanism for the degradation of acid golden yellow dye}

Identification of possible intermediate products during the dye decolorisation is the best way to understand the biodegradation reaction mechanism. There were five major intermediates after 
dye decolorisation which had been certificated by using $\mathrm{m} / \mathrm{z}$ values of the mass spectra. By revealing the formation of several aromatic intermediates with LC-MS spectra, it suggested that the dye molecule was proposed to be firstly attacked at two positions, namely the C-N single bonds attached to the central benzene as shown in Figure 5. Thus the dye molecule could be divided into diphenylamine and azo part. Afterwards, the chromosphere centers of azo part $(-\mathrm{N}=\mathrm{N}-)$, (Hisaindee et al. 2013) was cleaved to obtain two kinds of the lower molecular-weight products including M-aminobenzenesulfonic acid and aniline. Meantime, the diphenylamine was also proposed to be further degraded which produced aniline and benzene. Compared to the original structure of acid golden yellow dye, these intermediate products obtained by co-immobilization dye decolorisation could be treated more easily for wastewater disposal than untreated dye molecules, which the light aromatic hydrocarbons could be degraded in natural environment. (Fuchs et al. 2011) Furthermore, the total organic carbon (TOC) was observed in Figure 5. It was seen that TOC decreased obviously in 7 days which represented the co-immobilization was effectively to degrade dye molecules. However, due to the existence of benzene ring, the white-rot fungus co-immobilization should be considered as the pre-treatment but not be used alone. 

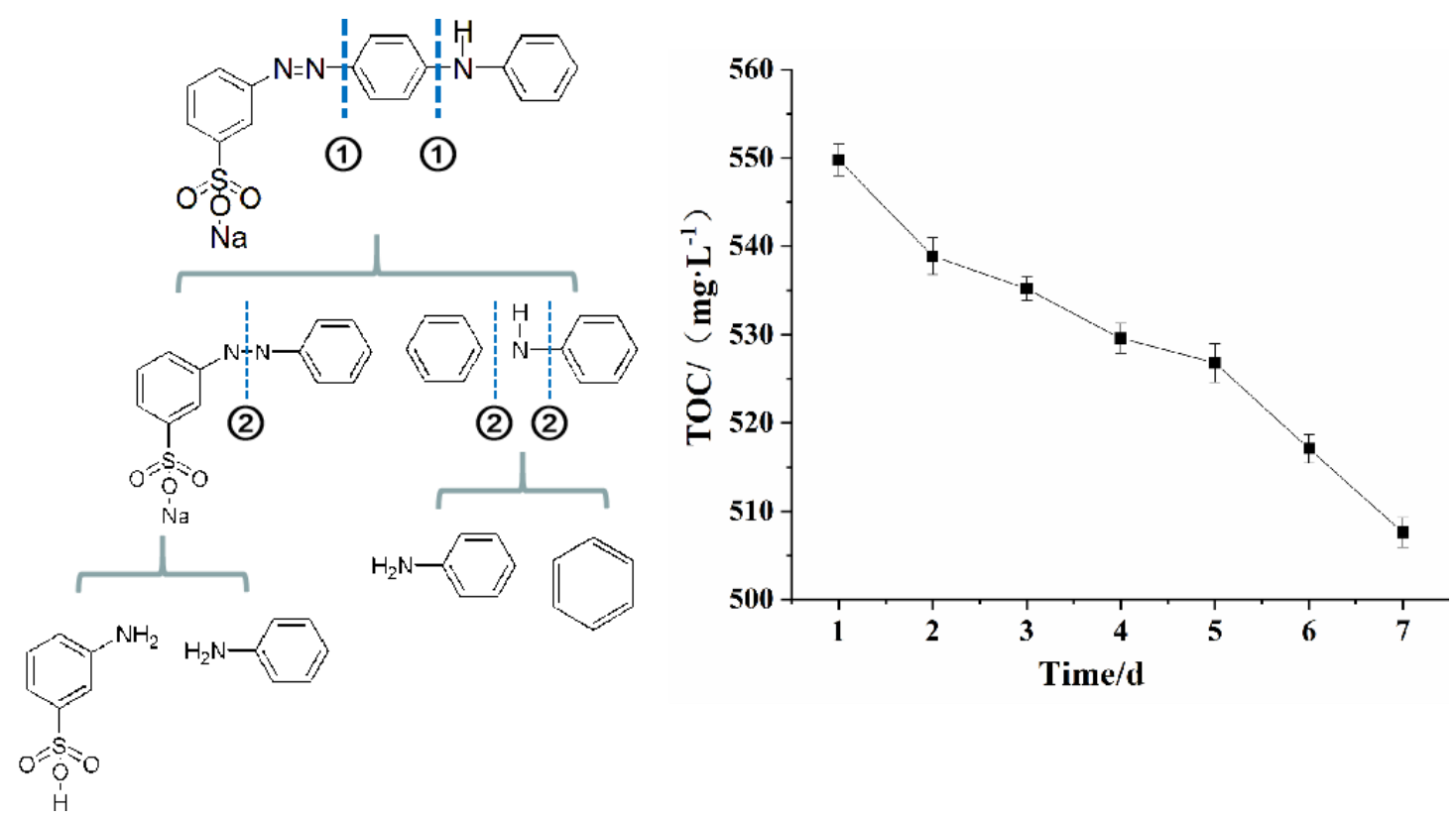

Figure 5. Influence of fungal immobilization to dye-retanning wastewater treatment

\section{Conclusion}

In this study, it evaluated the dye decolorisation effect of white-rot fungus immobilization treatment with different carriers to different dyes. Co-immobilization, which enjoys the advantages of both adsorption immobilization and entrapment immobilization, was selected for dye decolorisation owing to its stability and recyclability. It found that the plant carriers were effective in white-rot fungus immobilization such as sorghum stalk and corn cob. The sorghum stalk - calcium-alginate gel spherical particle (SS-CGPB) has the most significant effect for dye decolorisation with co-immobilization, and the decolorisation rate reached $86.77 \%$ at 6 days. Meantime, these gel particles exhibited excellent dye decolorisation ability after 5 cycles thereby they could be reused successfully, which was meaningful to save cost and reduce secondary pollutants. By white-rot fungus co-immobilization, the $\mathrm{C}-\mathrm{N}$ single bonds attached to the central benzene in the dye molecule was proposed to be firstly attacked, and the chromosphere centers of azo part $(-\mathrm{N}=\mathrm{N}-)$ was further cleaved. Due to the degradation ability to dye molecular structure, the co-immobilization with Phanerochaete chrysosporium had potential for application as a 
pretreatment in the field of environmental biotechnology such as biodegradation of leather/textile dye effluents.

\section{Acknowledgements}

The authors would like to gratefully thank the support of the National Key Research and Development Program of China (2017YFB0308401).

\section{Reference}

1. Baratto MC;Juarez-Moreno K;Pogni R;Basosi R and Vazquez-Duhalt R EPR and LC-MS studies on the mechanism of industrial dye decolorization by versatile peroxidase from Bjerkandera adusta. Environ. Sci. Pollut. R. 2015, 22, (11), 8683-8692

2. Bilal M;Asgher M;Parra-Saldivar R;Hu H;Wang W;Zhang X and Iqbal HM Immobilized ligninolytic enzymes: an innovative and environmental responsive technology to tackle dye-based industrial pollutants-a review. Sci. Total. Environ. 2017, 576, 646-659

3. Chandra S;Das P;Bag S;Laha D and Pramanik P Synthesis, functionalization and bioimaging applications of highly fluorescent carbon nanoparticles. Nanoscale 2011, 3, (4), 1533-1540

4. Chaudhary P;Chhokar V;Choudhary P;Kumar A and Beniwal V Optimization of chromium and tannic acid bioremediation by Aspergillus niveus using Plackett-Burman design and response surface methodology. AMB Express 2017, 7, (1), 201

5. Fang Z; He C;Li Y;Chung KH;Xu C and Shi Q Fractionation and characterization of dissolved organic matter (DOM) in refinery wastewater by revised phase retention and ion-exchange adsorption solid phase extraction followed by ESI FT-ICR MS. Talanta 2017, 162, 466-473

6. Fuchs G;Boll M and Heider J Microbial degradation of aromatic compounds-from one strategy to four. Nat. Rev. Microbiol. 2011, 9, (11), 803

7. Hisaindee S;Meetani M and Rauf M Application of LC-MS to the analysis of advanced oxidation process (AOP) degradation of dye products and reaction mechanisms. Trac-trend Anal. Chem. 2013, $49, \quad 31-44$

8. Holkar CR;Pandit AB and Pinjari DV Kinetics of biological decolorisation of anthraquinone based Reactive Blue 19 using an isolated strain of Enterobacter sp. F NCIM 5545. Bioresource Technol. 2014, 173, 342-351

9. Kariminiaae-Hamedaani H-R;Sakurai A and Sakakibara M Decolorization of synthetic dyes by a new manganese peroxidase-producing white rot fungus. Dyes Pigments. 2007, 72, (2), 157-162

10. Natarajan TS;Thomas M;Natarajan K;Bajaj HC and Tayade RJ Study on UV-LED/TiO2 process for degradation of Rhodamine B dye. Chem. Eng. J. 2011, 169, (1-3), 126-134

11. Rauf MA;Meetani MA;Khaleel A and Ahmed A Photocatalytic degradation of methylene blue using a mixed catalyst and product analysis by LC/MS. Chem. Eng. J. 2010, 157, (2-3), 373-378

12. Riley R;Salamov AA;Brown DW;Nagy LG, et al. Extensive sampling of basidiomycete genomes demonstrates inadequacy of the white-rot/brown-rot paradigm for wood decay fungi. P. Natl. Acad. Sci.

USA. 2014, 111, (27), 9923-9928

13. Rushton $B$ and Mokaya $R$ Mesoporous boron nitride and boron-nitride-carbon materials from mesoporous silica templates. J. Mater. Chem. A 2008, 18, (2), 235-241 
14. Saratale RG;Saratale GD;Chang J-S and Govindwar S Bacterial decolorization and degradation of azo dyes: a review. J. Taiwan Inst. Chem. E. 2011, 42, (1), 138-157

15. Varjani SJ Microbial degradation of petroleum hydrocarbons. Bioresource Technol. 2017, 223, 277-286

16. Yang L;Wang $\mathrm{H} ; \mathrm{Lv} \mathrm{Y}$;Bai $\mathrm{Y}$, et al. Construction of a rapid feather-degrading bacterium by overexpression of a highly efficient alkaline keratinase in its parent strain Bacillus amyloliquefaciens K11. J. Agr. Food. Chem. 2015, 64, (1), 78-84

17. Yao P;Cen J;Fang M;Wang T and Wang Q A study on the preparation of pitch-based high-strength columnar activated carbon and mechanism of phenol adsorption from aqueous solution. RSC Adv. 2018, $8,(31), \quad 17558-17568$

18. Zhang $\mathrm{K} ; \mathrm{Xu} \mathrm{Y} ; \mathrm{Hua} \mathrm{X} ; \mathrm{Han} \mathrm{H}$, et al. An intensified degradation of phenanthrene with macroporous alginate-lignin beads immobilized Phanerochaete chrysosporium. Biochem. Eng. J. 2008, 41, (3), 251-257

19. Zhao Y-Q;Lu M;Tao P-Y;Zhang Y-J, et al. Hierarchically porous and heteroatom doped carbon derived from tobacco rods for supercapacitors. J. Power Sources 2016, 307, 391-400 